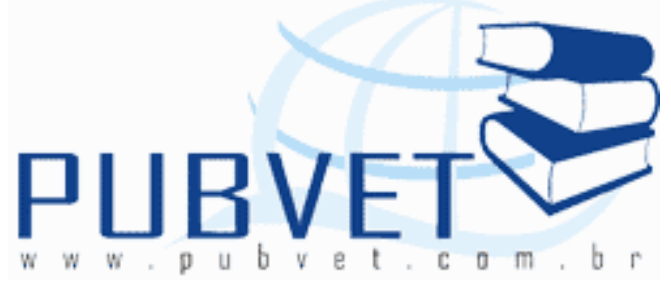

PUBVET, Publicações em Medicina Veterinária e Zootecnia.

\title{
Relação entre duração de partos e porcentagem de nascidos vivos e natimortos em suínos
}

Driene Bastos Soares ${ }^{1}$; João Paulo Rodrigues Bueno ${ }^{1}$; Isabella Lourenço dos Santos ${ }^{1}$; Marina Cruvinel Assunção Silva ${ }^{1}$; Fabrício Borges Duarte ${ }^{2}$; Bernardo José Rezende²; Mara Regina Bueno de Mattos Nascimento ${ }^{3}$

${ }^{1}$ Medico Veterinário, Mestrando em Ciências Veterinárias - Produção Animal na Universidade Federal de Uberlândia - UFU.

${ }^{2}$ Médico Veterinário.

${ }^{3}$ Professora Doutora da Faculdade de Medicina Veterinária da Universidade Federal de Uberlândia

\section{Resumo}

São vários os fatores que influenciam no número de leitões nascidos vivos, e um dos principais é a duração do parto. Assim, o presente trabalho teve como objetivo avaliar a duração do parto e a quantidade de leitões nascidos vivos e mortos. Foram analisados 10235 (dez mil duzentos e trinta e cinco) partos de matrizes de suínos cruzadas Large White $x$ Landrace no período de janeiro de 2007 a dezembro de 2008. Os fatores avaliados foram, a quantidade de leitões nascidos vivos, natimortos e incidência de partos, relacionando-os com a duração dos partos. Observou-se que os partos com duração maior que 6 horas obtiveram maior porcentagem de natimortos, a duração entre 2 a 3 horas tiveram o maior número de animais vivos. Conclui-se que o parto para 
ter melhor eficiência deve ter duração entre 1 a 3 horas sendo, portanto, esta uma boa característica para seleção das matrizes.

Palavras-chave: matrizes, leitões, nascimentos.

\title{
Relationship between duration of births, percentage of living and born in swine stillbirths
}

\begin{abstract}
There are several factors that influence the number of piglets born alive, and one of the leading and duration of delivery. Thus, the present study aimed to evaluate the duration of delivery and the amount of piglets born alive and dead. We analyzed 10235 (ten thousand two hundred thirty-five) births to mothers pig Large White $x$ Landrace cross from January 2007 to December 2008. The factors evaluated were the number of piglets born alive, stillborn piglets and incidence of births, relating them to the length of calving. It was observed that the deliveries lasting longer than 6 hours had higher percentage of stillborn, the duration between 2 to 3 hours had the greatest number of live animals. It is concluded that for better delivery efficiency should last for 1 to 3 hours and therefore a good characteristics for this selection matrices.
\end{abstract} Keywords: gilts, piglets, births.

\section{INTRODUÇÃO}

$\mathrm{Na}$ suinocultura tecnificada, a produtividade do rebanho pode ser analisada pelo número de leitões desmamados/fêmea/ano (VARGAS, A.J. et al., 2001), fazendo parte desse contexto o número de leitões nascidos vivos é altamente influenciado pelo parto. O parto é considerado uma das etapas mais críticas da suinocultura. Por isso, a fêmea parturiente deve receber assistência constante, tanto durante o parto quanto nos momentos que o antecedem (PEIXOTO, C.H. et al., 2001). 
O número de leitões nascidos vivos depende, em parte, da duração do parto, sendo que a rápida e eficiente expulsão dos fetos, o manejo e o seu acompanhamento fazem com que o mesmo seja bem sucedido. (SOBESTIANSKY, J. et al., 1998).

A duração do parto pode variar de duas a seis horas, sendo considerado patológico quando esse tempo é superado. Alguns estudos sugerem que quanto maior o tempo de parição, maior será o número de natimortos. Agentes estressantes tendem a induzir a maior duração do parto por liberação de adrenalina, que interfere na liberação de ocitocina, diminuindo as contrações uterinas, que também são influenciadas pelo cálcio e quando em falta aumentam também a duração do parto. (SOBESTIANSKY, J. et al., 1998).

Outros fatores como mortalidade embrionária, natimortalidade, podem influenciar negativamente na eficiência reprodutiva, reduzindo os valores leitões desmamados/ fêmea/ano e com isso ocasionado prejuízo ao produtor. (LISBOA, M.N.T.S., 1996)

Ainda segundo Lisboa, M.N.T.S. (1996), a mortalidade na espécie suína pode atingir altos índices do nascimento a desmama, de 15 a $18 \%$, dentro desses índices, para (VARGAS, A.J. et al., 2001), 5 a 9,7\% morrem durante o parto e esta ocorrência de leitões natimortos, em geral está associada à anoxia fetal, pelo rompimento do cordão umbilical, o que é bastante comum em partos demorados e distócicos.

A natimortalidade é a principal causa de mortalidade de leitões, sendo significativamente relacionada com o número de leitões desmamados/fêmea/ano (DIAL, G.D. et al., 1992).

O presente trabalho objetivou analisar a duração dos partos influenciando a quantidade e viabilidade dos leitões nascidos.

\section{MATERIAL E MÉTODOS}

Foram utilizados dados de 10235 partos de matrizes de suínos cruzadas Large White $x$ Landrace de uma granja de Minas Gerais, que tem sistema de 
criação intensivo e os partos são referentes ao período de Janeiro de 2007 a Dezembro de 2008. Nesses animais foram analisados a quantidade de leitões nascidos vivos, leitões natimortos e incidência de partos, todas as características relacionadas a duração dos partos.

\section{RESULTADOS E DISCUSSÃO}

Na tabela 1 podemos visualizar que a maior incidência de natimortos ocorre em partos com mais de 6 horas de duração e segundo Sobestiansky, J. et al., (1998) estes tipos de partos são considerados patológicos. A quantidade de nascidos vivos foi maior nos partos com período de duração de 2 a 3 horas e menor no período de mais de 6 horas, já, os natimortos foram menos nos períodos de 1 a 2 horas, também confirmados por Sobestiansky, J. et al., (1998) que relata que a incidência de nascidos vivos é maior quando o parto é rápido e ocorre eficiência na expulsão dos fetos e conseqüentemente maior os natimortos em longas durações de parto. Esta correlação pode ser explicada por aumentar as possibilidades de ocorrer anoxia fetal, rompimento do cordão umbilical, o que é bastante comum em partos demorados (WENTZ, I. et al., 2006).

Comparando-se as incidências, a propriedade possui uma considerável quantidade de animais com 2 a 3 horas de duração dos partos e um menor número de natimortos, portanto é interessante fazer uma seleção para animais com duração dos partos entre 1 a 3 horas sendo os períodos com maior número de nascidos vivos e menor natimortos confirmados por (Lisboa) e (WENTZ, I. et al., 2006), além do que, reduz a necessidade e custo de mãode-obra acompanhando os partos o que é fundamental segundo (PEIXOTO, C.H. et al., 2001) para bons índices de nascidos vivos. 
Tabela 1: Quantidade de leitões nascidos vivos, leitões natimortos e incidência de partos, correlacionadas a duração dos partos, em uma granja de suínos de Minas Gerais, 2007/2008.

\begin{tabular}{lllll}
\hline $\begin{array}{l}\text { Duração } \\
\text { dos partos }\end{array}$ & $\begin{array}{l}\text { Incidência } \\
\text { dos partos }\end{array}$ & Nascidos vivos & Natimortos & Outros \\
\hline 0 a 1 hora & 149 & $91.90 \%$ & $4.42 \%$ & $3.68 \%$ \\
1 a 2 horas & 1476 & $93.51 \%$ & $3.39 \%$ & $3.10 \%$ \\
2 a 3 horas & 2150 & $93.75 \%$ & $3.68 \%$ & $2.57 \%$ \\
3 a 4 horas & 1819 & $93.29 \%$ & $4.01 \%$ & $2.70 \%$ \\
4 a 5 horas & 1437 & $92.86 \%$ & $4.48 \%$ & $2.66 \%$ \\
5 a 6 horas & 1004 & $92.31 \%$ & $4.76 \%$ & $2.93 \%$ \\
Mais de 6 & & & & \\
horas & 2200 & $90.95 \%$ & $5.94 \%$ & $3.12 \%$ \\
Total & $\mathbf{1 0 2 3 5}$ & & & \\
\hline
\end{tabular}

\section{CONCLUSÕES}

Através deste trabalho podemos concluir que a duração dos partos é um fator que deve ser observado, pois influencia nos índices de nascidos vivos e natimortos. Sabendo-se que quanto maior a duração do parto maior a incidência de natimortos. O período de 1 a 3 horas é o mais eficiente, portanto um critério interessante para selecionar matrizes suínas.

\section{REFERÊNCIAS BIBLIOGRÁFICAS}

DIAL, G.D. et al. Reproductive failure: differential diagnosis. In: LEMAN, A.D. et al. Diseases of swine. 7th. Ed. Iowa State University Press, Ames, IA. p. 88-137. 1992. 
PEIXOTO, C.H. et al. Utilização de dois análogos sintéticos de prostaglandina F2a, Dinoprost e Cloprostenol, pela via submucosa vulvar na indução de partos em suínos. In: CONGRESSO BRASILEIRO DE VETERINÁRIOS ESPECIALISTAS EM SUÍNOS, 10., 2001, Porto Alegre. Anais ... Porto Alegre: ABRAVES, 2001, p. 191-192.

SOBESTIANSKY, J. et al. Suinocultura intensiva: produção, manejo e saúde do rebanho. Brasília: Embrapa, Serviço de Produção de Informação. 1998.

VARGAS, A.J. et al. Comportamento estral de primíparas suína submetidas à terapia hormonal com eCG associado ao hCG. In CONGRESSO BRASILEIRO DE VETERINÁRIO ESPECIALISTAS EM SUÍNOS, 10., 2001, Porto Alegre Anais... Porto Alegre: ABRAVES, 2001, p. 181-182.

WENTZ, I. et al. Fatores de risco para leitões natimortos e mumificados. In: CONGRESSO LATINO-AMERICANO DE SUINOCULTURA, 3., 2006, Foz do Iguaçu, Anais... Foz do Iguaçu, 2006. p. 271-288. 